\title{
VERDADE E REALIDADE NA HISTORIOGRAFIA ANTIGA
}

\author{
Henrique Cairus*
}

RESUMO: This paper intends to propose a review on the concepts surrounding the analysis of the historiographical production during Antiquity, such as: truth, reality, data, testimony, evidence, facts, res ficta and res gesta. It was intended to focus on the eldest reception perspective in these works.

PALAVRAS-CHAVE: História Antiga, Verdade, Realidade, Dados, Testemunho, Provas, Res Ficta, Res Gesta.

O projeto deste artigo é o de prestar alguma contribuição àqueles que trabalham com textos historiográficos antigos no que tange à relação entre verdade, realidade, dados, testemunhos, provas e fatos, pensando essas categorias a partir da própria historiografia antiga.

Antes, contudo, é preciso dizer que, a par de querelas filosóficas infindas, o que tomamos por realidade aqui é o que também poderíamos chamar de dado ou de feixe bruto de dados desprovido de qualquer elaboração mental e reunido sob a égide do acaso ou da conjuntura. Qualquer intervenção humana nesses dados integra um projeto consciente ou inconsciente de elaboração da verdade. A realidade, para a história, é o

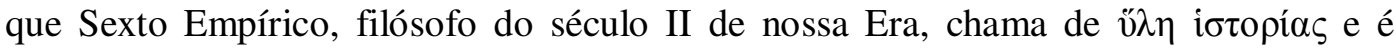
$\dot{\alpha} \mu \dot{\varepsilon} \theta$ odos (Aduersus mathematicos, I, 266). Talvez, contudo, não seja nem isso, mas ainda assim não se lhe pode negar a concretude que dá consistência à própria verdade.

Fica dito, desde já, que a verdade é uma construção, mas a realidade, não.

Durante muitos séculos, acreditou-se numa factualidade pura. Essa, aliás, foi, nesses mesmos séculos, o norte das narrativas históricas e, pouco mais tarde, da disciplina história. Ao historiador cabia a narração dos fatos no tempo, ao geógrafo a descrição dos fatos no espaço e ao filósofo cabia superar ambos, pensando para além do tempo e do espaço, ainda que pensando essas mesmas categorias.

Um historiador que se dedicasse à Antiguidade, como Edward Gibbon, no século XVII, ou Fustel de Coulanges, no século XIX, obrigatoriamente tinha uma enorme erudição e um profundo conhecimento das fontes primárias, que eram também julgadas por um critério de fidedignidade com diversos compromissos. Além de narrar e avaliar os dados, o historiador podia também depreender alguma lição a partir dos fatos. A narrativa dos fatos é moralizante porque a história era feita de erros e acertos.

Há, na Retórica a Herênio, obra do século I a.C., uma distinção entre dois

* Professor de Língua e Literatura Gregas da Universidade Federal do Rio de Janeiro e Universidade de São Paulo. Este artigo
baseia-se na conferência que proferida na Faculdade de Ciências e Letras de Araraquara, Universidade do Estadual Paulista, em setembro de 2010 . 
gêneros de narração, o que se apóia nas ações (negotia) e o que se apóia nos personagens (personae). A narração que se baseia nos negotia divide-se em três, a fábula, a história e o argumento:

A fábula contém ações que não são nem verdadeiras nem verossímeis (ueri similes), como as relatadas na tragédia. A história são as ações realmente empreendidas (res gesta), mas em época distante da nossa lembrança. O argumento é a ação ficta (res ficta) que, no entanto, poderia ter acontecido, como o argumento da comédia (I, 12).

Fabula est, quae neque ueras neque ueri similes continent res, ut eae sunt, quae tragoedis traditae sunt. Historia est gesta res, sed ab aetatis nostrae memoria remota. Argumentum est ficta res, quae tamen fieri potuit, uelut argumenta comoediarum.

Quintiliano (Institutio Oratória, II, 4, 2) segue essa mesma direção, acrescentando que a fabula é distanciada não só da verdade, mas também da forma da verdade (non a ueritate modo sed etiam a forma ueritatis remota), e o argumentum é "falso, mas semelhante ao verdadeiro, que as comédias figuram" (quod falsum sed uero simile comoediae fingunt) A história, por sua vez, é a expositio gestae rei, e tanto robustior quanto uerior.

\begin{tabular}{|c|c|c|c|c|}
\hline & $\begin{array}{c}\text { Aristóteles } \\
\text { Poética, 1415a }\end{array}$ & $\begin{array}{c}\text { Rec a Herênio } \\
\text { I,12 }\end{array}$ & $\begin{array}{l}\text { Sexto Empírico } \\
\text { Ad.mach., I,266 }\end{array}$ & $\begin{array}{c}\text { Quintiliano } \\
\text { Instiuto Oratoria, II, } 4,2\end{array}$ \\
\hline História & $\begin{array}{l}\text { rà Yevópeva } \\
\text { critério alético }\end{array}$ & $\begin{array}{l}\text { res gesta } \\
\text { critério alético }\end{array}$ & $\begin{array}{l}\text { tà үevópeva } \\
\text { critério alético }\end{array}$ & $\begin{array}{l}\text { expositio gestae rei } \\
\text { cricério de elaboração }\end{array}$ \\
\hline$\mu \tilde{\theta} \theta$ os / fabula & argumento (?) & $\begin{array}{l}\text { ueri simile } \\
\text { cricério de } \\
\text { verossimilhança }\end{array}$ & 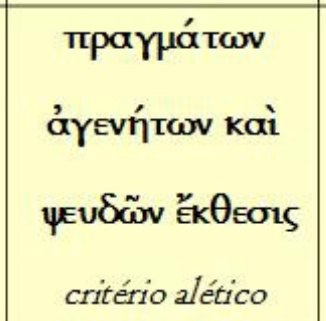 & $\begin{array}{l}\text { non a ueritate modo sed } \\
\text { etiam a forma ueritatis } \\
\text { retmota } \\
\text { cricério alécico }\end{array}$ \\
\hline $\begin{array}{l}\pi \lambda \alpha ́ \sigma \mu \alpha / \\
\text { argumentum }\end{array}$ & & $\begin{array}{c}\text { res ficta } \\
\text { cricério de elaboração }\end{array}$ & 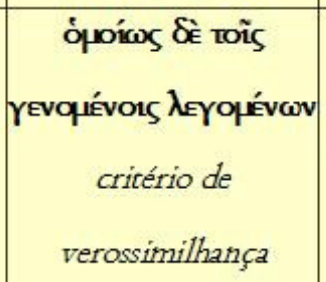 & $\begin{array}{l}\text { quod falsum sed uero } \\
\text { simile comoediae fingunt } \\
\text { critério de verossimilhança }\end{array}$ \\
\hline $\begin{array}{l}\text { poesia } \\
\text { critério de } \\
\text { verossimilhança }\end{array}$ & 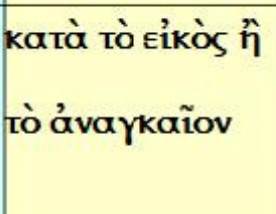 & & & \\
\hline
\end{tabular}

Sexto Empírico, no primeiro livro de seu Aduersus mathematicos ${ }_{2}$ traduziu ao grego não o texto, mas a idéia do autor da Retórica a Herênio, interpretando os termoschave dessa abordagem teórica da seguinte maneira: fabula (ueri similes) por $\mu \tilde{v} \theta$ os;

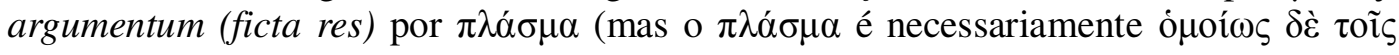




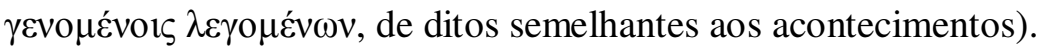

Jean de Garlande, no século XIII, numa obra intitulada Parisiana poetria, propõe novamente, a distinção entre res gesta e res ficta, distinguindo, assim, pelo critério de verdade, a história da ficção. O uso do termo res gesta já denuncia, em si, sua apropriação da historiografia latina antiga como modelo. Fazendo ressoar, nessa idéia, a conhecida distinção aristotélica entre a poesia e a história:

É evidente também pelo que foi dito que não é tarefa do poeta dizer o que ocorreu ( $\tau \grave{\alpha} \gamma \varepsilon v o ́ \mu \varepsilon v \alpha$ ), mas o que poderia acontecer, as coisas possíveis conforme a verossimilhança ou a necessidade

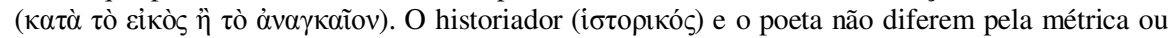
pela ausência dela (pois, ainda que os escritos de Heródoto fossem colocados em métrica não deixariam de ser, com ou sem métrica, alguma história), mas diferenciam-se por isso, por que um diz o que aconteceu ( $\tau \grave{\alpha} \gamma \varepsilon v o ́ \mu \varepsilon v \alpha$ ) e o outro o que poderia acontecer. Por isso a poesia é também

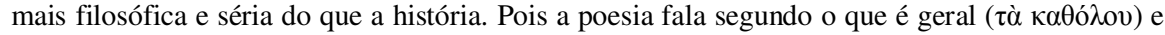

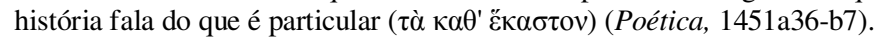

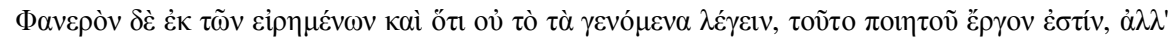

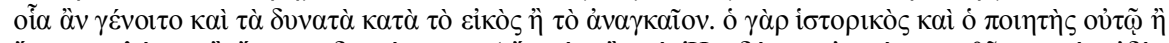

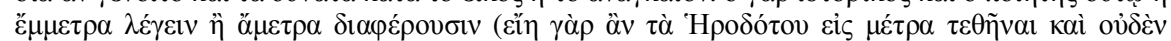

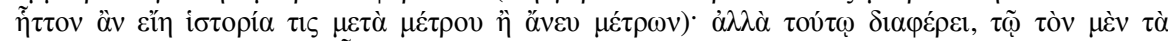

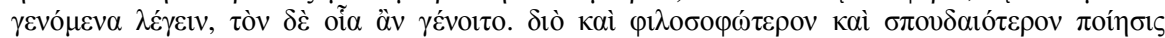

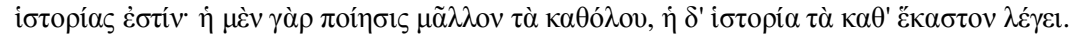

A história está, portanto, submetida ao critério alético, expresso por Sexto Empírico precisamente nesses termos, em que o gênero se contrapõe a tudo que for da

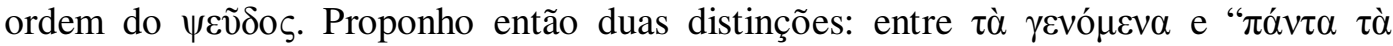

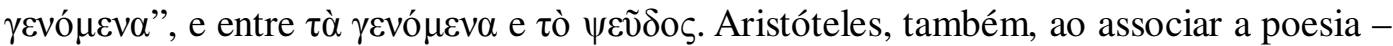

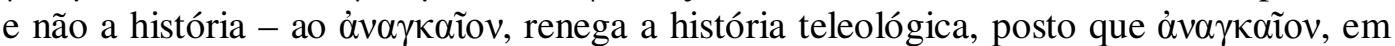
toda a obra aristotélica sobrevivente, relaciona o efeito à causa, nessa ordem. E isso, para Aristóteles, e também para nós, não pertence ao campo da história.

Nesse ponto, evoco o proêmio de Heródoto, que oferece um projeto de escrita historiográfica que pautou todo o gênero desde então:

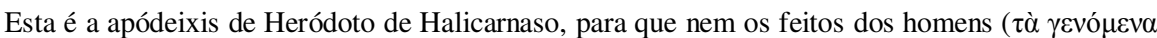

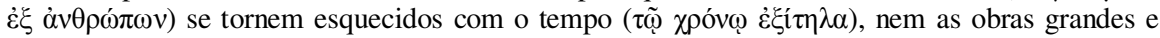

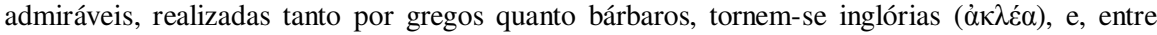
outras coisas, a causa pela qual lutaram entre si (Heródoto, Histórias, Proêmio).

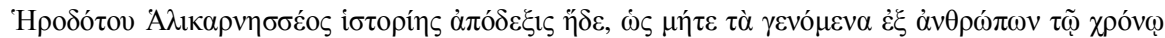

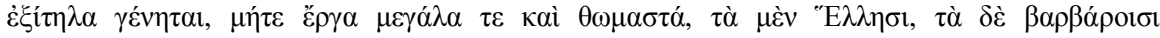

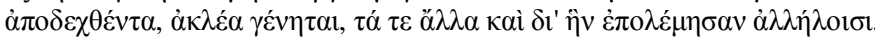

Os pontos cardeais do projeto herodotiano são, portanto: 1) o relato dos feitos humanos; 2) a preservação da memória; 3) a imparcialidade; 4) a atribuição de valor por meio da

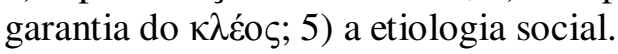

O termo $\gamma \varepsilon v o ́ \mu \varepsilon v \alpha$ no Proêmio não parece ter o comprometimento com o critério alético que parece ter nos autores que já vimos. Heródoto tem uma consciência maior de seu poder demiúrgico. O que realmente impressiona na obra de Heródoto é a subordinação da verdade ao seu projeto. Parece haver ali uma noção precisa do papel que o historiador tem de administrar os dados, de gerenciar a realidade, a fim de constituir a verdade.

Mas Heródoto vai além.

Movida e guiada pelo $\theta \alpha \tilde{u} \mu \alpha$, sua escritura dá um passo fatal para o gênero historiográfico: ela consegue desassociar a verdade da realidade. 
O "Lógos de Creso", no Livro I, contém o famoso encontro fictício entre Sólon e Creso, personagens, que, conquanto factuais, não são contemporâneas. Plutarco, na Vida de Sólon (I, 23), comenta o episódio do encontro narrado por Heródoto, afirmando

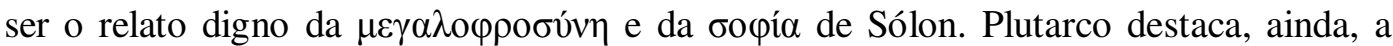
distinção entre os $\tilde{\eta} \theta \eta$ grego e bárbaro. Segundo Tatiana Ribeiro, que investigou pormenorizadamente o episódio: "Toda a carga simbólica do episódio herodotiano encontra o reconhecimento de Plutarco, que, então, não se exime de recriá-lo na biografia de Sólon" (2005, p. 59).

Como entender a presença de uma narrativa de factualidade histórica praticamente nula nas Histórias de Heródoto?

Bronislaw Bacsko (1985, p. 296), que parece partilhar com Cassirer a idéia de "simbólico", defende que o dispositivo simbólico é responsável pela construção de fatos por uma sociedade, e adentram a memória coletiva, sobrepujando os acontecimentos que isoladamente lhe deram origem. É como se, a partir dos cacos de vasos semelhantes desde sempre quebrados, fosse montado outro vaso, que, conquanto da mesma matéria de seus antecessores, sabe-se que nunca antes existira, mas, ainda assim, se olha para a peça e se pode dizer: assim era o vaso.

Não há dúvidas de que esse é o processo mais ousado da elaboração da verdade histórica, mas, seja qual for o processo outro, os dados sempre serão nossos cacos.

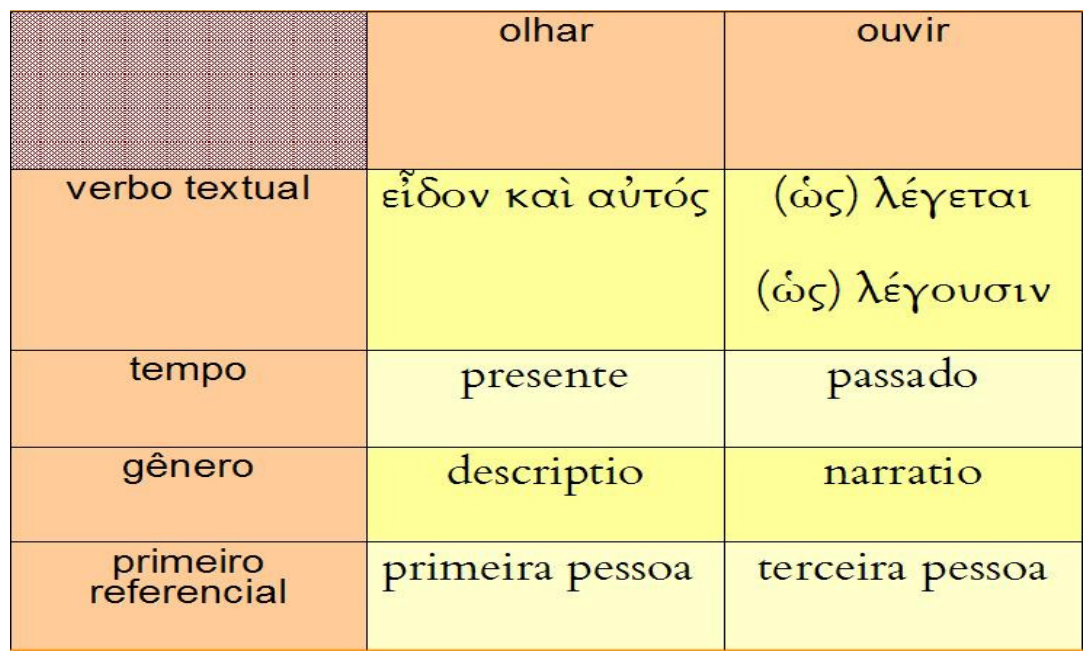

Primeiramente é preciso dizer que a escrita de Heródoto, e, por conseguinte, boa parte da historiografia antiga (da qual destaco, nesse particular, a obra de Plutarco) opera em dois eixos, o da descrição, baseado sobretudo no olhar, e o da narrativa, fundamentado no ouvir. O primeiro implica na presença e no presente, e o segundo, na ausência e no passado. Sem que possamos desconsiderar a narratio em meio à descriptio, e, menos freqüentemente, o contrário.

Tal variação axial permite um movimento de aproximação e de distanciamento que interfere diretamente na carga de comprometimento do autor com o grau de factualidade do objeto. Mas ainda assim, não se trata aqui de verossimilhança, mas de veracidade. 


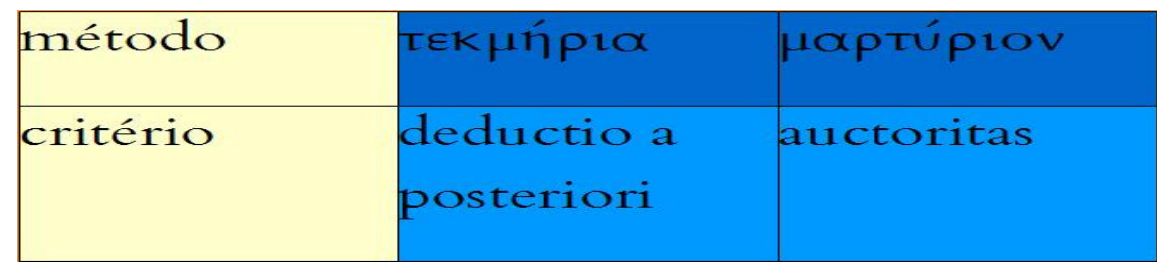

Apesar de sabermos hoje que não foi factual o encontro entre Sólon e Creso, não é questionável o grau de veracidade dado a ele no discurso herodotiano. Nem o grau de veracidade nem o senso simbólico de evidência inconteste.

A verdade é depositada sobre dados que podem ser constituídos de diversas $\tilde{i} \lambda \alpha$, mas que invariavelmente se apóiam em dois métodos: os $\mu \alpha \rho \tau v \rho \rho \alpha$, próprios ou alheios, mais freqüentemente do ouvir, associados a um $\lambda \varepsilon ́ \gamma o v \sigma r$ ou a algum de seus cognatos, e os $\tau \varepsilon \kappa \mu \eta ́ p ı$, que são construções dedutivas invertidas, mas de grande apelo retórico.

Tomemos dois exemplos de Heródoto:

Os egípcios foram os primeiros homens a fazer esses festejos e essas pompas e esses cortejos, e os gregos aprenderam isso deles. Meu $\boldsymbol{\varepsilon \kappa \mu \eta ́ p ~}$ muito tempo, enquanto os dos gregos foram feitos mais recentemente (II, 58).

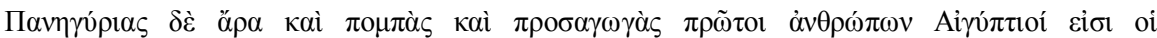

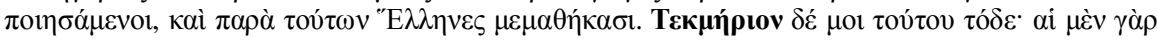

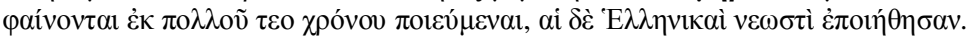

E ainda mais este:

Que [os fenícios] aprenderam [a circuncisão] relacionando-se com o Egito, meu grande $\tau \varepsilon \kappa \mu \eta ́ p ı$ ov disso é este: Todos os fenícios que se relacionam com a Grécia já não mais imitam os egípcios quanto às partes pudendas, mas não mais circuncidam os genitais de seus epígonos (II, 104).

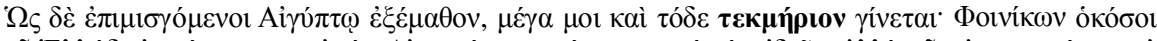

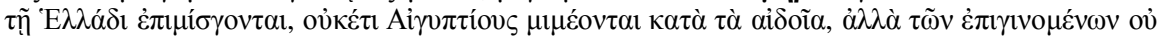

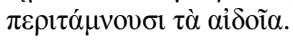

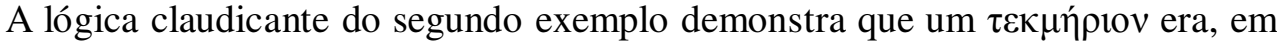
Heródoto, freqüentemente um indício frágil, e sempre decorrente da constatação, e

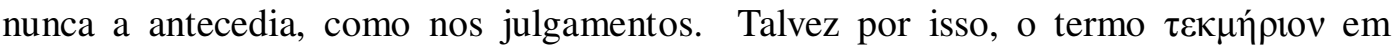
Heródoto venha constantemente modulado por um " $\mu$ oı", ao contrário do que acontece

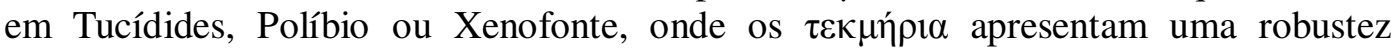
argumentativa mais condizente com os hábitos jurídicos e com a importância que esse

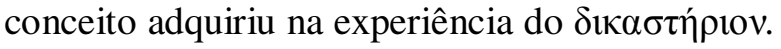

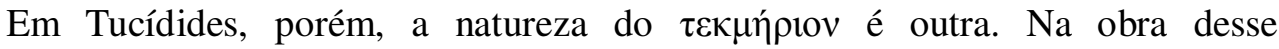

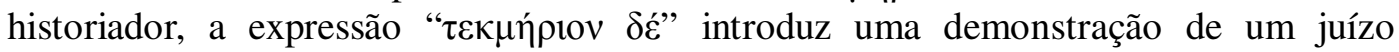
emitido imediatamente antes. A idéia é, evidentemente, avigorar o crédito, como neste exemplo:

O caráter geral da doença vai para além do lógos, e, de várias formas diferentemente, sobrecaiu a cada um, de maneira mais ofensiva do que a esperada pela natureza humana, e, nesse aspecto, mostrou-se diferente das doenças habituais: pois as aves e os quadrúpedes que comem muitas vezes humanos que estavam insepultos ou não se aproximavam deles ou pereciam se os comiam. A prova é que as aves desse tipo se tornavam notoriamente raras, e não eram vistas em volta de nenhum dos cadáveres e nem em outro lugar; por outro lado, os cães sentiam mais os 
acontecimentos, pois levam a vida com os homens ${ }^{1}$ (História da Guerra do Peloponeso, II, 50).

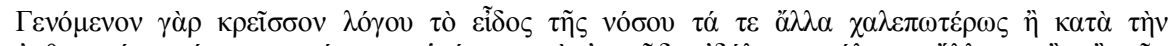

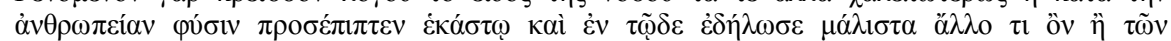

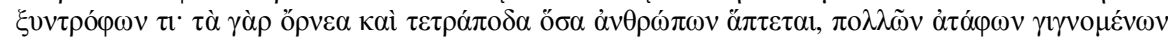

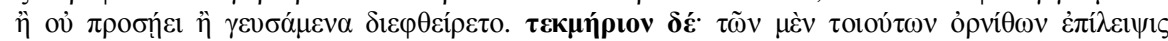

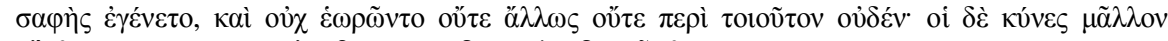

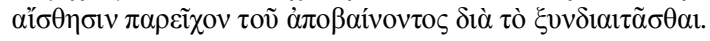

O lugar de fala do historiador estava entre uma narrativa ou uma descrição que soava épica e, portanto, era cercada de uma auctoritas quase sagrada, e a retórica précodificada, que dialoga com o discurso epidítico e até mesmo com o judiciário.

É preciso que se diga que, de uma forma ou de outra, o que está em questão não é exatamente o convencimento, mas uma busca por um grau de crença mais elevado, para usar a expressão que Paul Veyne consagrou. O historiador disputa o território da fides de seus ouvintes ou leitores, e essa fides tem uma natureza diversa da fides religiosa. Ela opera em um setor relacionado a um tempo passado não tão remoto a ponto de ser religioso, nem tão próximo a ponto de imiscuir-se a uma apreensão direta da realidade por outros filtros.

A urdidura da verdade histórica é uma operação discursiva que exige uma medida de distanciamento que, embora larga, não pode ser forçada, sob pena de se perder a credibilidade, por um lado, ou o poder de mediação, por outro.

A memória assume um papel fundamental nesse tecido discursivo, uma vez que ela é precisamente o acervo de dados computado sob a égide do simbólico. E o simbólico sustenta e mantém todo o imaginário social.

Uma conhecida frase de Tucídides vale a pena ser relembrada neste momento. No livro II (54) de sua Guerra do Peloponeso, o historiador comenta nestes termos a consulta feita ao oráculo sobre a peste:

Em seu infortúnio, lembraram-se, como era natural, do seguinte verso que, segundo os mais velhos entre eles, fora recitado havia muito tempo: "Virá um dia a guerra dórica, e com ela a

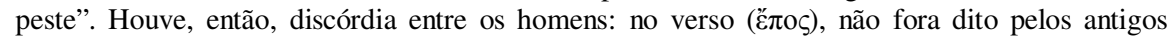

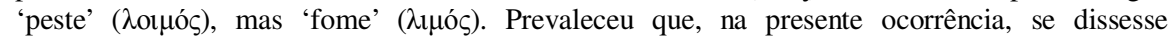

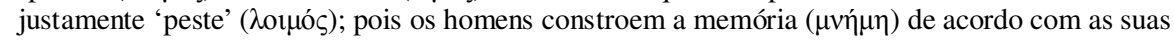

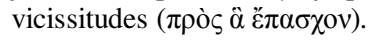

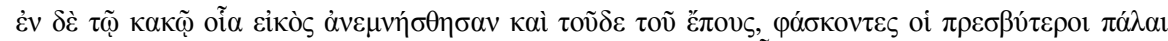
$\alpha \delta \varepsilon \sigma \theta \alpha i$ '

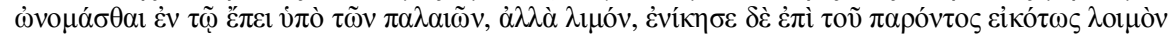

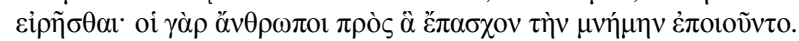

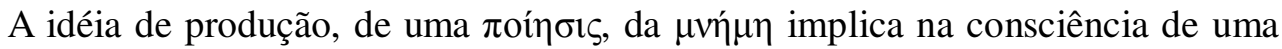

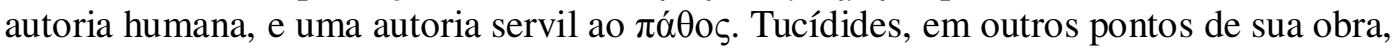
insiste nessa valiosa idéia. Um exemplo igualmente ilustrativo está também no livro segundo:

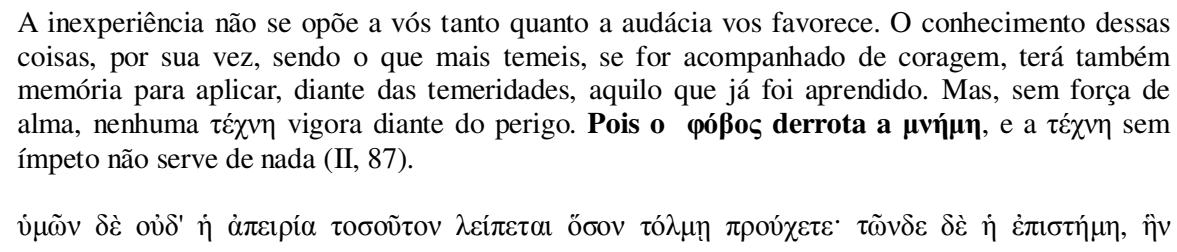

1 Tradução de Andréa Draeger (2004, p. 80).

Organon, Porto Alegre, $\mathrm{n}^{\circ}$ 49, julho-dezembro, 2010, p.59-68 


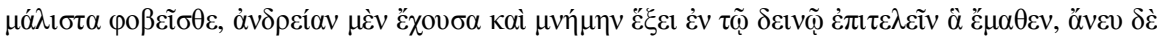

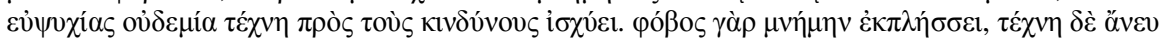

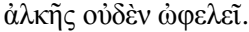

A memória é o primeiro passo no recolhimento do feixe de dados que constituirá na matéria da escrita da história. Tucídides tem plena consciência disso. No seu

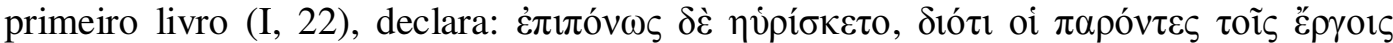

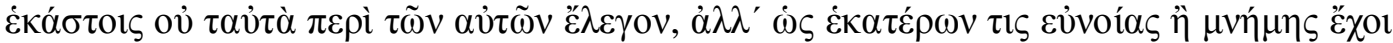
[Descobria-se com muito esforço, porque os contemporâneos a cada um dos feitos não diziam as mesmas coisas sobre eles, mas conforme suas simpatia ou memória].

Tucídides procurava, no entanto, evitar o que ele chamava de $\mu v \theta \tilde{\omega} \delta \varepsilon \varsigma$, o fato com feições de mito, mesmo sob pena de perder o interesse da audiência (II, 22). Tal alegação parece corroborar a hipótese de um compromisso ético do historiador relativamente a seu lugar e seu modo de fala, geradores de um gênero que logo seria categorizado. A recusa do $\mu \nu \theta \tilde{\omega} \delta \varepsilon \varsigma$ está em sintonia com os traços com os quais Aristóteles diferencia a História da poesia, sobretudo da poesia épica.

Toda a res gesta, enfim, é res ficta, mas nem toda a res ficta é res gesta. Os que se dedicam aos Estudos Clássicos não hesitam em pensar a historiografia como um gênero exatamente porque sabem ou intuem isso.

\section{BIBLIOGRAFIA}

BACSKO, Bronislaw. Imaginação social. In: Enciclopédia Einaudi, vol. 5: Antropos/homem. Lisboa: Imprensa Nacional/Casa da Moeda, 1985.

DRAEGER, Andréa. "Para além do lógos": a Peste de Atenas na obra de Tucídides [Dissertação de Mestrado]. Rio de Janeiro: UFRJ, 2004.

RIBEIRO, Tatiana Oliveira. Ólbos: uma discussão axiológica nas Histórias de Heródoto [Dissertação de Mestrado]. Rio de Janeiro: UFRJ, 2005 (Disponível em: www.letras.ufrj.br/proaera/cvtr.htm). 